\title{
The Construction and Perfection of Mental Health Education Model of Poor Students in Colleges and Universities \\ Shiwei Wu
}

\author{
Xianyang Normal University,Xianyang,712000,China \\ 16359150@qq.com
}

\begin{abstract}
Keywords: Poor Students In Colleges And Universities; Mental Health Education Model; Construction; Perfection
\end{abstract}

\begin{abstract}
The problem of poor students in Colleges and universities has a long history. With the transformation of China's economic system and the acceleration of the popularization of higher education, the problem of poor students has become a hot issue to be solved in the development of higher education in China. After entering the University, poor students are prone to psychological barriers due to their differences in material life. Based on the analysis of the current situation of psychological problems of impoverished college students, this paper makes a beneficial exploration of constructing and improving the mental health education mode of impoverished college students.
\end{abstract}

\section{Introduction}

With the transformation of China's economic system, the acceleration of the popularization of higher education and the reform of tuition system in Colleges and universities, the phenomenon of impoverished college students is very common. According to statistics, the proportion of impoverished students in China is about 20\% 30\%, and it is increasing year by year. The problem of the poor students in Colleges and universities has become the focus of the government, the education department, the society and the colleges and universities, and has become a hot issue to be solved in the development of higher education in China. Poor college students not only face economic difficulties and living difficulties, but also bear psychological pressure, such as self inferiority, self confidence, lack of self-confidence, tension and anxiety, difficulties in interpersonal communication, difficulties in learning, and difficulties in employment. If you can't get timely and appropriate help, these psychological pressures will not only affect their physical development and health, but also have a negative impact on their psychological and life attitude, which will affect their personal growth and development. Therefore, to understand and analyze the psychological status of poor students in Colleges and universities and to construct a scientific system of mental health education for poor students in Colleges and universities is the requirement for the development of higher education in the new period. It is also an effective way to help the poor students to successfully complete their studies and adult talents.

\section{Poor Students of the Hierarchy of Needs Analysis}

Maslow divides human needs into five categories: physiological needs, security needs, social needs, respect for demand and self realization needs, from lower to higher levels. Maslow's hierarchy of needs is a humanistic psychology and plays an important role in the study of organizational incentives. The demand for poor students in Colleges and universities is mainly in the following aspects.

Physiological (demand for food and clothing): This is the most primitive and basic demand of people. It is the strongest and unavoidable lowest demand. Because of the imbalance in the development of the eastern and western parts of our country, some "old, few, edge, poor" areas of college students, their families can not provide the most basic living expenses, such students can only rely on the state grants or national loans to live, the cost of living is as low as 200 yuan a month. It can be seen that the pressure of survival is the most fundamental and most direct pressure of the poor college students. This pressure has plagued the healthy development of college students 
for a long time, and eventually leads to serious mental health problems.

Safety (psychological) demand: if the physiological needs are met, then the psychological needs that follow are: hope to be free from unfair treatment, learn to cope with the ability and confidence. But poor college students are relatively poor in their learning ability and learning because of their relatively poor learning base in high school and learning conditions, such as the relative poor English listening and speaking, and the lack of art and sports skills. All these will lead poor students to be in a disadvantageous position in the learning and life of University, and their learning confidence is frustrated, and their psychological security needs are not satisfied.

Social needs: this means that people are eager to get care, love and understanding from family, friends, colleagues and groups, which is the need for friendship, love and so on. Compared with physiological needs and security needs, social needs are more subtle and more difficult to perceive. It shows in the college life that it hopes to maintain friendship and partnership with students, to be concerned with each other, to be a member of a class or a community, to be able to talk with friends and to get a sense of belonging. However, for some college poor students, due to different living conditions, differences in ideas and economic conditions, their own character tends to be more introverted, which further exacerbates the difficulties of interpersonal communication and leads to mental health problems.

\section{Psychological Status of Poor Students in Colleges and Universities}

Self esteem and inferiority complex. Self esteem is one of the core factors of personality, and it is also a normal demand of human beings. Although many poor students have poor family economic conditions, they shoulder the great expectations of their parents' elders, and hope to change their family and their own destiny through their hard work. They pay great attention to the external performance, his feisty, strong self-esteem. Strong self-esteem is easy to lead them to succeed and fail. It also forms a fragile self-esteem that can not afford setbacks. Many poor students are very difficult to live in school. Because they are afraid of the respect of teachers and students, they think "short" of other students, low self evaluation, few words, some poor students are afraid of other students to discriminate against their own family economic conditions, so that their family's actual situation is deliberately concealed. The poor students who participated in the school decided to refuse to accept the support from the state, the society and the schools, thus creating an overly inferiority mentality and thus affecting the growth of the poor students.

Anxiety and anxiety. Poor students are closely connected with their families economically and emotionally. The difficulty or sudden change from time to time at home will bring them emotional shock and anxiety. Some poor students with poor basic learning base, though very diligent in reading, are not ideal, such as computer application and poor English speaking ability. Some will make them feel nervous, anxious, even self reproach, and feel sorry for their parents and family members who are hard working and eager for themselves; the pressure of employment will make them restless and unsure; and more because of the difficulties of living, learning and life without a stable and reliable economic guarantee, busy life, neither economic strength nor economic strength, There is no more time and energy for interpersonal communication, and the diversity and reciprocity of interpersonal communication in college students also cause certain psychological pressure for the poor students. In the past, they have the psychology of tension and depression.

Weariness and dependence on psychology. Because of the economic difficulties, poor students can not have the same learning tools as electronic dictionaries and computers as other students, and the modern education skills are low. Therefore, it is necessary for the poor students to pay more effort to adapt to the learning environment of the University. Some students, after a period of adjustment, can basically adapt to the new environment, some poor students can not successfully complete this transformation, can not adapt to the new environment, lack of basic interpersonal knowledge and skills, easily lead to interpersonal conflict and self psychological fortification, they are more isolated, depressed, learning and life are affected, learning is not in the eye. Mark can't interest and produce weariness psychology. Some impoverished students even indulge in the Internet. They feel great dissatisfaction with the real world and find comfort in the virtual world.

Some poor students think that they are the most unfortunate people in the world. They do not 
want to stand up to themselves, lose their courage to fight with their fate, and think that they can get help for granted. They are totally counting on the government and the support of the school and society and relying on the strong psychology.

Sensitive and suspicious mentality. When a poor student talked about his recent psychological experience, he said, "in my mind, I always feel depressed. I can't get rid of anyone who can't help me." Ask his reason, he confessed: "high school, everyone's economic conditions are almost all, the students are very good, after the University, the gap is too big, some students I and he greeted him, he ignored me..." Poor students, because of family economic reasons, emotional instability, low emotional control ability, more sensitive and suspicious, self respecting, often a little thing can stimulate their self-esteem, for other people's behavior is very concerned, afraid of the students to discuss their shortcomings, mockery.

\section{Analysis of the Psychological Status of Poor College Students}

The desire for self fulfillment is strong. Although the government, the educational administrative department, the University and the whole society are paying attention to and helping the poor students, this concern and help mainly focus on the economic level, the strength of financial aid is increasing year by year, and the benefits of poverty are growing increasingly. But we must help the needy students, in addition to material, we should also give real spiritual care, so that we can overcome difficulties both physically and psychologically. On the basis of the study of human needs and motives, American psychologist A.H.Maslow puts forward the famous hierarchy of needs. He believes that self realization is the desire of self exertion and self perfection, and the tendency to realize his potential. Everyone wants to realize himself, this is the highest level. It is necessary for poor students, the economic burden, the high expectations of the family, and other factors, the desire to realize themselves is stronger, in some poor areas, poor families, for a child after reading the University for four or five years have consumed all, even debt tired, the students from these areas and families are more expected to achieve it. The ideal goal is, therefore, the enormous psychological pressure brought by the unification of ideal and reality is imaginable.

Because of financial difficulties, there are many difficulties and great pressure. Poor students are more difficult than ordinary students because of financial difficulties. They are mainly poor in material, difficult to live, difficult to adapt to the learning environment of the University, difficulty in learning, tension in interpersonal relations, difficulties in interpersonal communication, and relatively weak cultural base and basic skills. A group of 724 poor students and 897 non impoverished students in Harbin Engineering University were tested by cartel 16PF test. The test data were analyzed by cluster analysis, single factor analysis of variance and LSD multiple comparison analysis. The results showed that the personality of the poor students and the non impoverished students had obvious differences, and the group performance of the poor students. The characteristics of impoverished students are psychological instability and anxiety.

The Pressure of Employment. Because of their own economic conditions and weak social background, poor students are more difficult to find a good job. They can only rely on their own struggle, face the high cost of employment, bear the long cherished wish, the heavy support of the family, they bear great pressure on the body and mind, and this is a serious situation in the present situation of the overall employment of college students. The stress of the body and mind is more prominent.

\section{Models of Mental Health Education of Poor Students Thinking}

Building up a team of teachers in Mental Health Education. In order to give poor students timely and effective psychological assistance, first of all, we should establish a professional and high quality professional psychological health education teachers. They should pay attention and intervention to the psychological barriers and psychological crisis of poor students, and formulate practical and feasible psychological education programs, such as opening mental health lectures, conducting psychological consultation activities, and realistically Peer education and so on. Secondly, we should strengthen the construction of part-time psychological health education teachers, counselors and class teachers are the most suitable part-time psychological health 
education teachers, because the counselors and class teachers are the most direct contacts of students in the school. They can master the psychological state of the poor students in the shortest time and take the initiative to intervene. Third, we should set up the curriculum of psychological education for the poor students, through the way of classroom teaching, let the mental health education go into the classroom, transmit the relevant knowledge to the students in the form of teaching, and enhance the students' consciousness of self health care.

To carry out psychological counseling of poor students groups. Individual counseling is the process of direct communication between college counselors and poor students, and the psychological counseling of poor students is the process of communication between college counselors through specific group situations and facing many poor students. Due to various forms of group counseling, impoverished students are interested in attracting poor students to invest actively. In group activities, for every poor student, it is both a "help man" and a "helping person". Through the guidance of psychological counselors, in group psychological activities, impoverished students can imitate their behaviors and find their own problems. It can not only effectively affect or change some of the wrong ideas or ideas, but also help solve other people's problems.

Compared with individual counseling, group counseling for impoverished students has the characteristics of high efficiency and good effect. Group psychological counseling for impoverished students can not only greatly increase the number of needy students, but also save time and manpower for tutoring. The advantages of the poor students' group psychological counselling are also reflected in the prevention of the problems in the bud, avoiding the one-sided nature of the poor students' observation problems, and making use of the collective activities to let all the poor students discuss the problems and solutions of the poor students' psychology. Through the colorful group activities, we can help poor students set up a positive mindset so as to better solve their mental health problems.

The situation of psychological counseling for the poor students is a recurrence of a social activity, providing a chance for the participants to communicate with others, trying to show themselves truly, and advocating a positive attitude and way to solve their own problems, especially for some poor students who have excessive self-esteem, inferiority and poor interpersonal relations. In a group scene full of trust and good atmosphere, by means of demonstration, imitation, help and help, we find that they are lack of trust in others, too degrading themselves, and poor interpersonal communication, so as to change their wrong behavior and establish good interpersonal relationship with other participants. And this kind of change will also extend into the real life, that is, the role of group counseling is transferred to daily life, and the psychological shortcomings of the group will be changed gradually, which makes the effect of the poor students' group psychological counselling be sustainable.

Strengthen consumer education, correct view of material.To strengthen the education of the consumption concept of poor students, not too much value and respect for money, but also do not look at money like manure, to achieve reasonable consumption, to save the province as much as possible, can not save the place to be generous. Thrift has always been a virtue advocated by the Chinese nation, and will never be out of date. For students without much income, this virtue needs to be publicized and practiced. However, in the deep level of investment, such as higher education and professional training, the poor students should also try to charge themselves as much as possible, as the saying "money should be used on the edge of the knife". Through various ways, we can make poor students form the correct consumption concept, treat money and material correctly, and form a clearer consumption concept.

Improve the four level work network mental health education system for poor students. The four level work network system of mental health education for poor students mainly refers to: (1) school psychological health education and consultation center, which is the main channel to dredge the psychological pressure of poor students, is an important way to prevent psychological diseases and optimize psychological quality, and also an important part of mental health education; (2) the psychological guidance Station of the College (Department) is the heart of the school. The extension of the health education institutions; (3) the class psychological Committee directly faced 
with the students in the class and grasps the students' dynamics; (4) the dormitory psychological information worker. The four level work network system works through group consultation, individual consultation, psychological hotline, network platform and letter five in one. It has formed an effective working mode to guide the psychological pressure of poor students and improve the psychological quality of poor students.

We should improve the support system for the aid of poor students. To solve the problems of poor students' economic difficulties is the premise to solve the psychological problems of poor students. Up to now, colleges and universities have established a diversified subsidy policy system based on scholarships, student loans, work assistantships, special difficulties subsidies and tuition remission. However, the financial support system for poor students should be continuously improved, to further establish and improve the loan system and relevant regulations of college students, to improve the amount and facet of the scholarships, to actively broaden the way of work study and to create more opportunities for students to work in school, and to carry out the credit system to allow some outstanding poor students. To graduate in advance; to strive for financial support from all sectors of the society and people from all walks of life to establish a variety of social reward funds to enable poor students to develop healthily in a relatively relaxed environment.

We should strengthen the construction of campus culture and build a harmonious interpersonal environment. Good campus culture can imperceptibly lead the healthy growth of college students, and also for poor students. On the one hand, the colorful and healthy campus activities can enrich the amateur life of the poor students. On the other hand, they can cultivate their positive and optimistic attitude; in the rich activities, it is beneficial to the poor students to play a special role, and to establish a harmonious interpersonal relationship in the activities, to relieve their psychological pressure and to enhance their confidence in life. A good campus culture, a correct outlook on life and values, and a world outlook education can enhance the ability of poor students to bear setbacks and help them grow into a useful person to society and to others.

\section{Conclusion}

Poverty is a kind of hardship for life, and it is also a valuable asset. There must be a variety of rich material poverty, the poverty of material is not terrible, the terrible is the barren spirit, and the most terrible is the dual lack of material and spirit. It is necessary for the poor students to have a healthy mind and a complete and sound personality. They need the joint efforts of the whole society, universities and all health educators to converge the emotions into rivers of love, to bring rich nutrients to all poor students and nourish the mind and body. The mental health education of the poor students should be based on the people-oriented, through the correct methods and strategies to guide them, to take appropriate measures to solve practical problems for them and help them go out of the predicament and move towards a bright future.

\section{References}

[1]YALE UNIVERSITY. University Tuition Rates1996-1997to2006-2007[EB/OL]. http://www.yale.edu/oir/open/pdf_public/W082_Tuits.U.pdf:2006-11-09.

[2] NATIONAL CENTER FOR EDUCATION STATISTICS. Digest of Education Statistics 2006[EB/OL]. http://nces.ed.gov/pubs2007/2007017.pdf:2007-07-26.

[3] ARTHUR M HAUPTMAN. Have Federal Loans contributed to Higher Tuition?,ASHE Reader on Finance in Higher Education[M]. Pearson Custom Publishing,2001:250-252.

[4] IMMER W A HR J. The Affordability of Higher Education:A Review of Recent Survey Research[R]. Washington,DC:The National Center for Public Policy and Higher Education,2002.

[5] L.Chen,J.J.Peng.The Psychological Analysis of College Students in Poverty and the Countermeasures [ $\mathrm{J}]$.JOURNAL OF NANHUA UNIVERSITY ( SOCIAL SCIENCE EDITION), 2004,2.

[6] NATIONAL CENTER FOR EDUCATION STATISTICS. Average undergraduate tuition and 
fees and room and board rotes charged for full-time students in degree -granting institutions, by type and control of institution:1964 -65 through 2005-06[EB/OL]. http://nces.ed.gov/pro-grams/digest/d06/tables/dt06_319.asp:2007-07-26.

[7] NATIONSL CENTER FOR EDUCATION STATISTICS. Student Financing of Undergraduate Education:2003 -04 Aid[EB/OL]. http://nces.ed.gov/pubs2006/2006153.pdf:2005-11-28.

[8] NATIONAL CENTER FOR EDUCATION STATISTICS. Enrollment in Post-secondary Institutions,Fall 2004; Graduation Rates, 1998 \& 2001 Cohorts; and Financial Statistics,Fiscal Year 2004[EB/OL]. 